\title{
sala \\ de

\section{POTENCIALIZANDO O ENSINO DE CIÊNCIAS NO ENSINO MÉDIO USANDO FERRAMENTAS TECNOLÓGICAS E METODOLOGIAS ATIVAS}

\section{POTENTIALIZING SCIENCE TEACHING IN HIGH SCHOOL USING TECHNOLOGICAL TOOLS AND ACTIVE METHODOLOGIES}

\author{
Edson Elias De Souza \\ prof_edson.fisica@hotmail.com \\ João Paulo Casaro Erthal \\ jperthal@gmail.com
}

\begin{abstract}
Resumo: este artigo expõe uma investigação que busca analisar as contribuições, para o ensino de ciência no Ensino Médio, de uma abordagem metodológica apoiada nas premissas da aprendizagem significativa desenvolvida por David Ausubel (1918 - 2008) e nas metodologias ativas de ensino: Sala de Aula Invertida, Ensino sob Medida e Instrução pelos Colegas. Com isso, foi elaborada uma Sequência Didática aplicada para estudantes da terceira série do Ensino Médio durante sete aulas. Partindo do princípio de que o conhecimento prévio do aluno é a variável que mais infuencia na aprendizagem significativa, a metodologia utilizada estimulou o aprendizado, proporcionando uma maior interação do aluno com novas metodologias de ensino e com simulações computacionais. Com a criação do grupo de Whatsapp, todos os materiais das aulas e as discussões eram feitas nesse ambiente, possibilitando aos alunos faltosos a possibilidade de acompanhar os conteúdos perdidos a qualquer hora e lugar. Podemos destacar que os alunos tiveram uma maior participação no processo de aprendizagem, passando a ser o centro do processo e o professor o mediador das ações.
\end{abstract}

Palavras-chaves: Metodologias Ativas. Aprendizagem Significativa.

\begin{abstract}
: this article exposes an investigation that seeks to analyze the contributions, for science teaching in high school, of a methodological approach supported by the premises of significant learning developed by David Ausubel (1918 - 2008) and in the active teaching methodologies: Flipped classroom, Customized Teaching and Instruction by Colleagues. As a result, a Didactic Sequence was developed for students in the third grade of High School during seven classes. Based on the principle, that the student's prior knowledge is the variable that most influences significant learning, the method used stimulated learning, providing greater student interaction with new teaching methodologies and computer simulations. With the creation of the Whatsapp group, all class materials and discussions were held in this environment, amaking it possible for absentee students to follow the contents on lost content at any time and place. We can highlight that the students had a greater participation in the learning process becoming the center of the process and the teacher, the mediator of the actions.
\end{abstract}

Keywords: Active Methodologies. Meaningful Learning.

\section{INTRODUÇÃO}

Este artigo é um relato de experiência de uma proposta de ensino da disciplina de Física, com foco no tema Física Nuclear, que objetivou buscar inovação para as metodologias aplicadas atualmente nas escolas, visto que o ensino precisa acompanhar os avanços tecnológicos.

No modelo de ensino usado na maioria das escolas, o método mais usual é o tradicional, com o professor no centro do processo de aprendizagem e o aluno sentado e registrando tudo que o 


\section{sala \\ de $\oplus$ em \\ aula foco}

-REVISTA ELETRONNICA

mestre fala, com pouca participação e reflexão. Este modelo tem mostrado, ao longo do tempo, que muitos alunos são propensos à aversão à matéria de Física por não visualizarem a utilidade prática do conteúdo ministrado nas aulas. Percebemos que este cenário de desmotivação e interesse reflete em todo o Ensino Médio, quando estudantes jovens e adolescentes não conseguem associar o que se aprende em sala de aula com o seu cotidiano.

Desse modo, essa pesquisa contribui significativamente, uma vez que segue as Orientações Educacionais Complementares aos Parâmetros Curriculares Nacionais (PCN+- Ensino Médio) de Física na Unidade 5.3, que afirma:
[...] "A presença do conhecimento de Física na escola média ganhou um novo sentido a partir das diretrizes apresentadas nos PCNEM. Trata-se de construir uma visão da Física voltada para a formação de um cidadão contemporâneo, atuante e solidário, com instrumentos para compreender, intervir e participar na realidade. Nesse sentido, mesmo os jovens que, após a conclusão do ensino médio, não venham a ter mais qualquer contato escolar com o conhecimento em Física, em outras instâncias profissionais ou universitárias, ainda terão adquirido a formação necessária para compreender e participar do mundo em que vivem [...]". (PCN+, p. 59).

Com a orientação, citada, fez-se necessária a criação de uma Sequência Didática (SD), que buscasse a transformação do estudante, que o fizesse compreender a ciência de maneira contemporânea e relacionada às tecnologias atuais.

\section{UNIDADE DE ENSINO POTENCIALMENTE SIGNIFICATIVA - UEPS}

Para criação de uma Sequência Didática de ensino que valorize os conhecimentos prévios do indivíduo, seguimos a proposta de Sequência Didática de Moreira (2011), chamada de Unidade de Ensino Potencialmente Significativa (UEPS), que tem como objetivo promover uma diferenciação progressiva, capacitar e internalizar as informações de maneira organizada, de modo que durante o processo seja possibilitada uma reconciliação integradora dos conceitos. Ainda, segundo Moreira (2011), a criação de uma UEPS passa por oito etapas, apresentadas a seguir.

\section{CONSTRUÇÃO DA UEPS SOBRE FISSÃO E FUSÃO NUCLEARES.}

Mostraremos, a seguir, as etapas da UEPS usadas na construção da SD, com principal enfoque no conceito de Física Nuclear, sendo elaboradas de acordo com as etapas propostas por Moreira (2011). 


\section{sala \\ de $\oplus$ em \\ aula foco}

10 Passo - Definir o tópico específico a ser abordado.

Tópicos: Estrutura Atômica, Modelo atômico, Radioatividade, Fissão e Fusão Nucleares.

20 Passo - Criar/propor situações que levem os alunos a externalizar seus conhecimentos prévios.

Foi entregue para os alunos uma atividade avaliativa com as seguintes questões: a) O que é um átomo? Quais as partes que o constituem? Faça um desenho representando um átomo. b) Por que não ocorre atração entre os elétrons e os prótons do mesmo átomo? c) - Qual (ais) a (s) cargas do elétron, próton e do nêutron?

3o Passo - Propor situações-problema em nível introdutório que levem em conta o conhecimento prévio do aluno.

Com o uso da Sala de Aula Invertida e do Ensino sobre Medida (EsM), os estudantes receberam várias Tarefas de Leitura e, de acordo com as dúvidas apresentadas, foram produzidas as questões da Instrução pelo colega (IpC).

40 Passo - Aprofundando o conhecimento.

Foi entregue aos estudantes, como Tarefas de Leitura, materiais introdutórios e videoaulas que aumentavam gradativamente o nível de conhecimento.

5 Passo - Nova situação-problema.

Para tal, foi realizada uma Aula Experimental sobre reações químicas e utilizados Simuladores Computacionais.

60 Passo - Diferenciação progressiva, por meio do diálogo e da apresentação de algumas situações.

Buscamos alcançar os objetivos dessa etapa por meio de Tarefas de Leitura, que partiam de conceitos mais gerais para conteúdos mais específicos. Foram sete Tarefas de Leitura, as quais apresentavam novas situações, exemplos e modelos sobre o assunto e propiciavam o diálogo e a discussão via redes sócias e em sala de aula. 


\section{sala \\ de $\oplus$ em \\ aula foco}

70 Passo - Avaliação Somativa ao longo de sua aplicação, registrando tudo que possa ser considerado evidência de aprendizagem significativa.

Para tal foram utilizadas as anotações no diário de bordo, registrando atividades avaliativas durante todo processo e uma prova tradicional no final da SD.

80 Passo - Avaliação da UEPS.

Foi elaborado um questionário de opinião apresentado no final da SD, no qual 95\% dos alunos aprovaram a metodologia utilizada. Com a análise dos dados, verificamos que houve indício de uma Aprendizagem Significativa.

\section{A SALA DE AULA INVERTIDA}

A Sala de Aula Invertida é uma metodologia em que os alunos estudam os conceitos em casa e chegam às aulas com dúvidas para serem discutidas com os professores. Por isso, a expressão invertida, pois é o aluno que explora em casa o conteúdo, compartilhando em sala suas dúvidas e questionamentos. Essa metodologia tem como objetivo promover aulas mais dinâmicas, uma vez que o modelo tradicional de exposição é cansativo e não propicia a participação protagonista do aluno.

\footnotetext{
"O conceito da metodologia é que, o que antes era feito na sala de aula do modelo tradicional, agora é executado em casa enquanto as atividades que eram realizadas sozinhas pelos alunos como tarefa de casa, agora são executadas em sala de aula" (BERGMANN; SAMS 2016, p. 11).
}

A Sala de Aula Invertida busca o desenvolvimento da autonomia diante dos conteúdos e coloca o estudante como o principal responsável por seu aprendizado.

\section{PEER INSTRUCTION - A INSTRUÇÃO POR COLEGAS (IPC)}

A Peer Instruction ou Instrução por Colegas foi proposta por Eric Mazur, da Universidade de Harvard (EUA), em 1991, em uma disciplina de Física Básica nessa mesma universidade e se difundiu rapidamente pelo mundo, em especial nos Estados Unidos, Canadá e Austrália, com o objetivo tanto de engajar os estudantes como de levantar dificuldades a respeito dos conteúdos de aula (ARAUJO; MAZUR, 2013). 


\section{sala \\ de $\oplus$ em \\ aula foco}

REVISTA ELETRÔNICA

ISSN 2316-7297

Esta metodologia ativa permite que os estudantes assumam posturas ativas em relação a seu processo de ensino-aprendizagem. A Instrução por Colegas é uma metodologia ativa de aprendizagem caracterizada pelo estudo prévio de materiais disponibilizados pelo professor, na apresentação de questões conceituais em sala de aula e na aprendizagem por meio de debates entre os alunos.

\section{JUST-IN TIME TEACHING - ENSINO SOB MEDIDA}

Segundo Araújo e Mazur (2013), o método Ensino sob Medida valoriza o conhecimento prévio do aluno, sendo que é a partir das dificuldades apresentadas pela turma que o professor planeja suas aulas. Este método também adota os estudos e leituras prévias e é subdivido em três etapas: tarefa de leitura sobre os conteúdos a serem discutidos; discussão em sala de aula sobre as tarefas de leitura; e atividade em grupo envolvendo os conceitos trabalhados nas tarefas de leitura e na discussão em sala de aula.

\section{DESENVOLVIMENTO DA SEQUÊNCIA DIDÁTICA}

Com base no exposto anteriormente, foi elaborada uma sequência didática pautada na utilização de metodologias ativas e orientada pela teoria da aprendizagem significativa de Ausubel. As atividades visavam a valorizar e conhecer os conceitos prévios dos estudantes, com intuito de se poder planejar com mais clareza as atividades a serem trabalhadas durante os encontros.

\section{PRIMEIRA AULA DA SEQUÊNCIA DIDÁTICA}

No início da primeira aula, apresentamos aos 40 alunos da 3ạ série do Ensino Médio a metodologia de ensino que seria trabalhada, detalhando cada etapa e seus objetivos, deixando claro para os alunos que o sucesso da SD dependeria do envolvimento deles no processo de aprendizagem.

Na sequência, aplicamos um pré-teste individual, utilizado como atividade avaliativa, que tinha como objetivo verificar os conhecimentos prévios dos alunos sobre o modelo atômico. Ao final da primeira aula, iniciou-se a utilização do método Ensino sob Medida, sendo entregue para cada estudante uma Tarefa de Leitura (TL) "texto 01" sobre o átomo e três questões avaliativas, para que os alunos pudessem ler, responder e enviar, junto com suas dúvidas, para o professor, dois dias antes da próxima aula. Nos últimos momentos da aula, foram formados grupos de até cinco alunos que iriam trabalhar 


\section{sala \\ de $\oplus$ em \\ aula foco}

juntos na aula seguinte e foi destacado o quanto era fundamental a leitura do texto para futuras atividades.

Criamos um grupo da turma no WhatsApp. Assim, enquanto surgiam as dúvidas, de qualquer lugar que estivessem, os alunos, por intermédio do aplicativo, encaminhavam-nas ao professor. Em posse destas dúvidas, o professor preparava a intervenção para a aula seguinte da SD.

\section{SEGUNDA AULA DA SEQUÊNCIA DIDÁTICA}

Nessa aula, foi utilizada a metodologia Peer Instruction que se caracteriza, principalmente, por promover a discussão de questões conceituais, entre os alunos, em sala de aula. Na sequência, temse o fluxograma de condução das atividades durante o método, o que é mostrado na Figura 1 a seguir:.

Figura 1. Fluxog

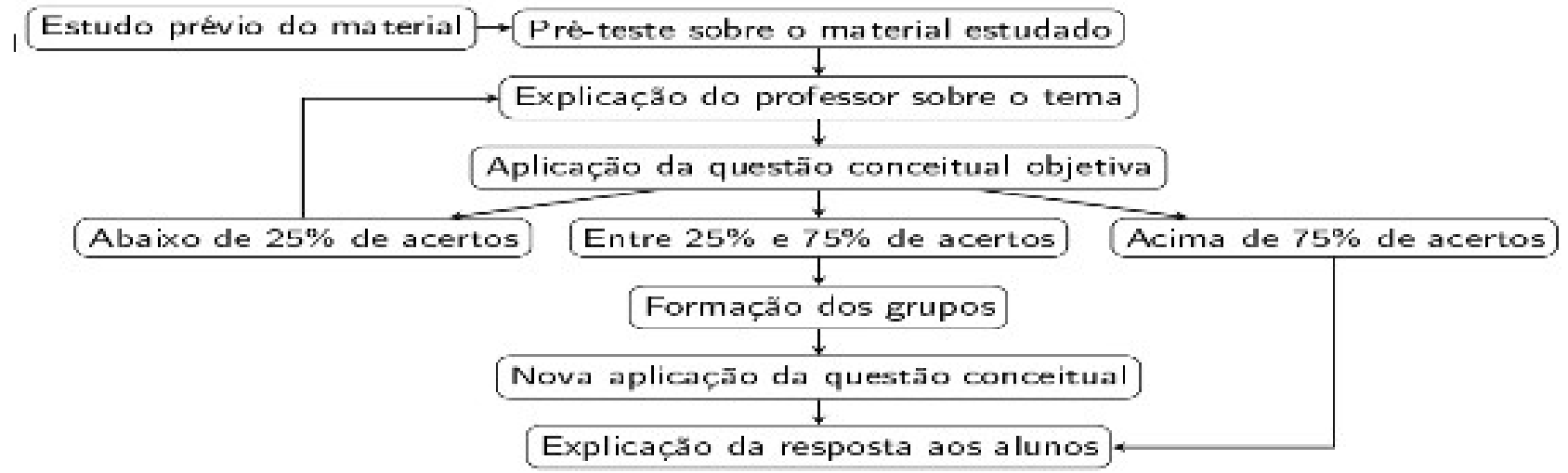

Fonte: Ferreira, 2017.

Trabalhamos seis questões conceituais sobre o tema, todas pautadas nas dúvidas enviadas pelos discentes ao professor. A aceitação e o engajamento por parte dos estudantes foram positivos durante esta aula.

\section{TERCEIRA AULA DA SEQUÊNCIA DIDÁTICA}

Cada grupo, no início da terceira aula, reproduziu o experimento sobre velocidade de uma reação e fez anotações de suas observações no roteiro entregue pelo professor.

Os grupos reproduziram os experimentos, explicando cada etapa para os colegas dos outros 


\section{sala \\ de $\oplus$ em \\ aula foco}

REVISTA ELETRÔNICA

grupos, além de filmar as apresentações, para postar no grupo da turma. Os vídeos postados, das apresentações dos experimentos, foram de suma importância para os estudos dos alunos, auxiliando a tirar as dúvidas dos estudantes e efetivando positivamente o uso da Sala de Aula Invertida.

Figura 2. Alunos reproduzindo e explicando os experimentos.

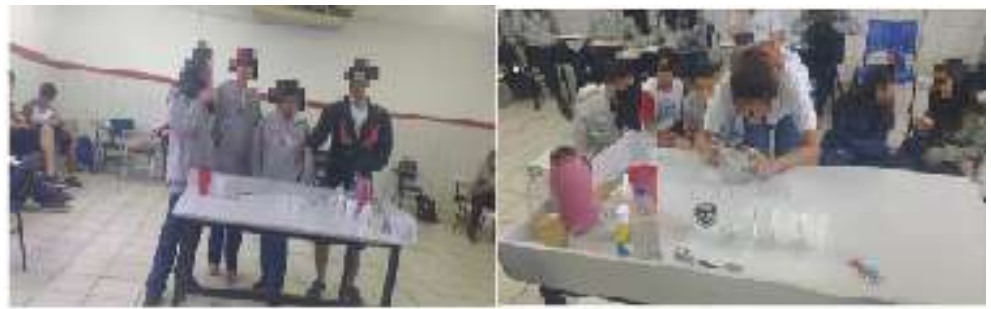

Fonte: Autor da pesquisa, 2019.

No final da terceira aula, os grupos receberam links de seis vídeos para que pudessem se preparar para a próxima aula. Esses vídeos e seus respectivos endereços são apresentados a seguir:

https://www.youtube.com/watch?v=SIB6fAzPW64

https://www.youtube.com/watch?v=P3s1k0zvp8E

https://www.youtube.com/watch?v=7CLlyqLqqMY

https://www.youtube.com/watch?v=f_Met4w9fDk

https://www.youtube.com/watch?v=LmCZpXv__OO

https://www.youtube.com/watch?v=nnBPU1f8grE\&feature=youtu.be

Essa atividade teve a finalidade de reforçar o conceito de força nuclear e ajudar os estudantes a responder às questões sobre forças nucleares a serem respondidas em casa (invertendo a sala de aula) e enviadas pela internet ao professor, até dois dias antes da próxima aula.

\section{QUARTA AULA DA SEQUÊNCIA DIDÁTICA}

Na quarta aula foram utilizados simuladores computacionais com intuito de despertar o interesse dos estudantes pelo tema e de elucidar melhor os conceitos discutidos. Foram disponibilizados um ou mais computadores para cada grupo e foi solicitado que cada grupo filmasse todas as etapas da simulação. Com o simulador do Phet funcionado, os estudantes simularam a reação de fissão nuclear e fizeram uma análise do gráfico de energia da reação. 


\section{sala \\ de \\ aula

Figura 3. Simulador de fissão nuclear

Reação de fissão nuclear

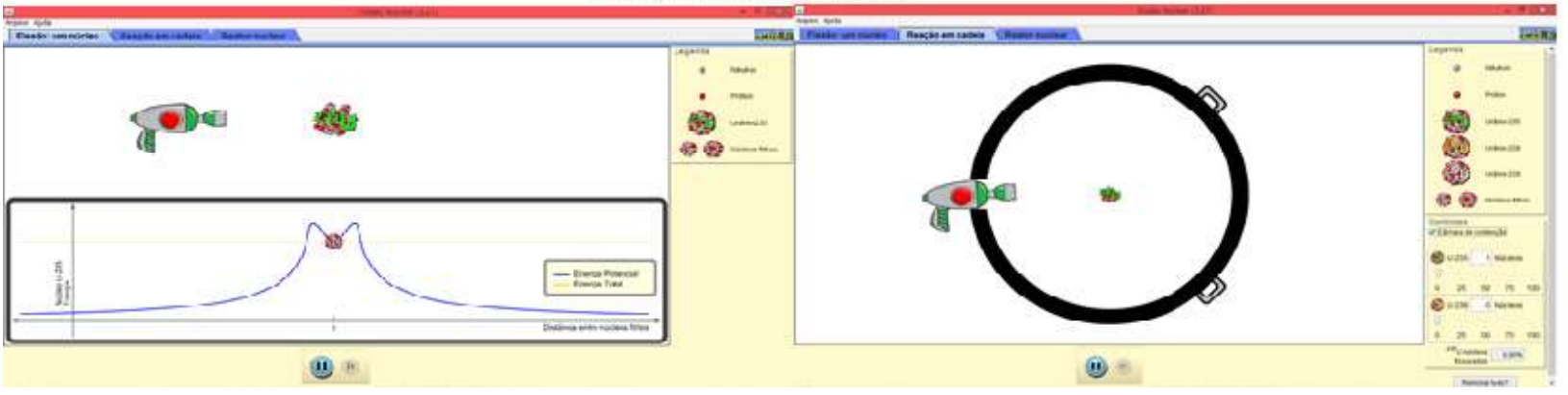

Fonte: Phet Interactive Simulations, 2019

Na sequência, os estudantes reproduziram uma reação em cadeia e ralataram passo a passo todo processo:

Figura 4. Reação em cadeia

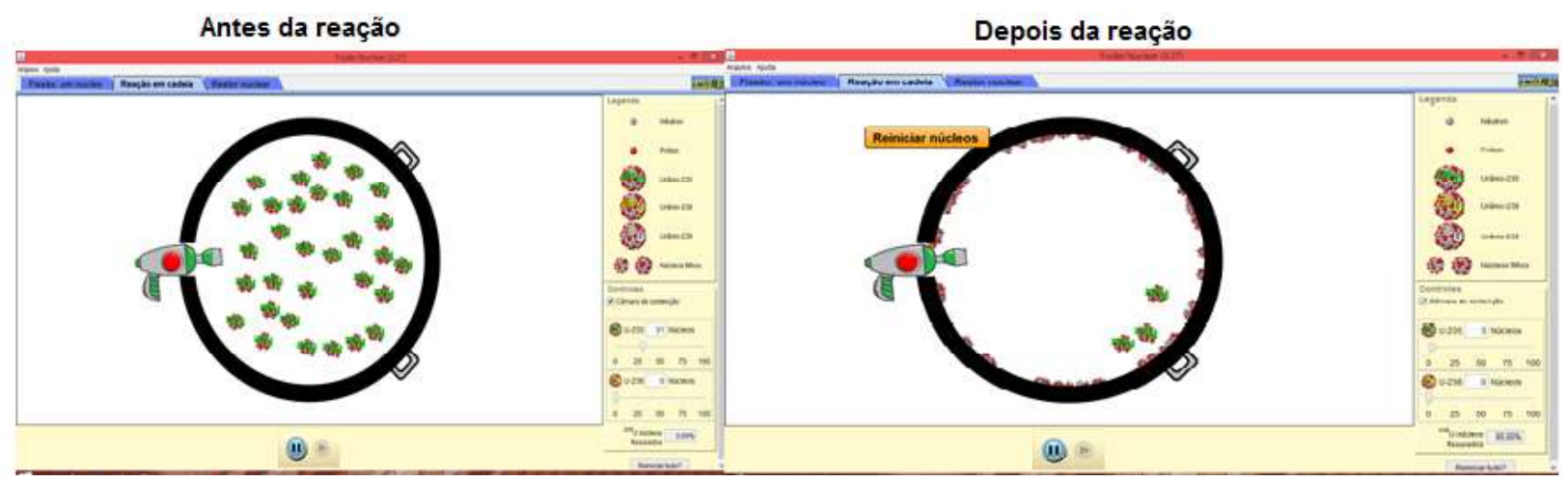

Fonte: Phet Interactive Simulations 2019

Ao final, os grupos reproduziram e comentaram o processo de fissão em um reator nuclear. Cada grupo produziu um resumo detalhado de todo processo e foi fornecida como Tarefa de Leitura dois vídeos, cujos links de acesso estão indicados a seguir, sobre o funcionamento de uma usina nuclear, seus benefícios e malefícios:

https://www.youtube.com/watch?v=hLiVmdnTSbQ https://www.youtube.com/watch?v=Px-wrOBfDMs

Antes de terminar a quarta aula, foram sorteados entre os grupos os temas dos seminários a serem apresentados na 5a e 6a aulas como atividade avaliativa. Segue o quadro de tópicos dos temas para apresentação dos seminários: 


\section{sala \\ de $\oplus$ em \\ aula foco}

-REVISTA ELETRÔNICA

Quadro 1. Temas do seminários

\begin{tabular}{|c|l|}
\hline Grupos & \multicolumn{1}{|c|}{ Temas } \\
\hline G1 & Funcionamento de aceleradores de partículas \\
\hline G2 & Origem do universo \\
\hline G3 & Processo de liberação de energia de uma bomba de hidrogênio \\
\hline G4 & Processo de liberação de energia de uma bomba de urânio \\
\hline G5 & Energia nuclear utilizada em armas de guerra: uso indevido e seus danos \\
\hline G6 & Usinas nucleares brasileiras e sua importância para a nossa matriz energética \\
\hline G7 & Diferenças entre fissão e fusão nuclear e suas aplicações \\
\hline G8 & Modelos Atômicos \\
\hline G9 & Radioatividade \\
\hline
\end{tabular}

Fonte: Autor da pesquisa, 2019.

\section{QUINTA E SEXTA AULAS DA SEQUÊNCIA DIDÁTICA}

Nessas aulas ocorreram as apresentações dos seminários. Tal atividade objetivou: verificar se houve ganho conceitual por parte dos alunos; estimular a relação do tema com o cotidiano; e observar se houve indícios de aprendizagem significativa. Cada apresentação teve no mínimo quinze minutos de duração e o professor, quando necessário, ajudou os discentes nas apresentações.

\section{SÉTIMA AULA DA SEQUÊNCIA DIDÁTICA}

Na última aula da Sequência Didática foi aplicada uma avaliação final individual com dez questões e um questionário de opinião, para que os estudantes avaliassem, sem se identificarem, a metodologia aplicada.

\section{RESULTADOS DA TURMA NA AVALIAÇÃO}

As avaliações foram realizadas por meio da aplicação de sete avaliações durante as SD, um pré-teste e um pós-teste final. O gráfico 1 mostra, de forma geral, o percentual médio de acertos e erros das questões discursivas. 


\section{sala \\ de $\oplus$ em \\ aula foco}

-REVISTA ELETRONNICA

Gráfico 1: Aproveitamento percentual médio da turma nas questões discursivas

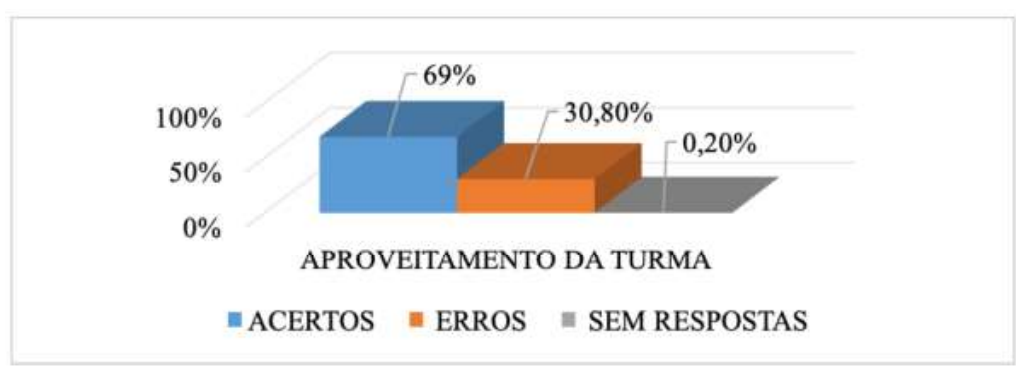

Fonte: Autor da pesquisa, 2019.

O gráfico 2 mostra o rendimento médio da turma nas questões objetivas de todas as avaliações.

Gráfico 2: Aproveitamento percentual médio da turma nas questões objetivas

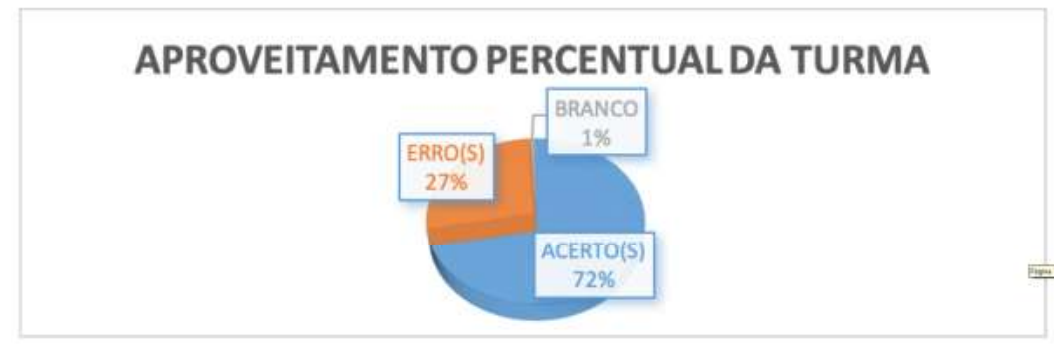

Fonte: Autor da pesquisa, 2019.

Com as análises dos resultados foi possível verificar que houve uma boa aceitação da nova metodologia, com uma média superior a $70 \%$ de acertos, e que as novas ferramentas: Sala de Aula Invertida, IpC e EsM, foram utilizadas de maneira proveitosa, não se esquecendo de citar que os erros cometidos mostraram que, para ocorrer uma aprendizagem mais aprimorada dos conteúdos, são necessários mais tempo e mais discussões sobre os temas.

A Sequência Didática aplicada promoveu uma ruptura do modelo de aulas tradicionais, bem como valorizou e potencializou os conhecimentos prévios já existentes na estrutura cognitiva dos estudantes.

\section{CONSIDERAÇÕES FINAIS}

Mediante o exposto, pode-se inferir que, a partir do estudo da Física Nuclear, por intermédio da Sequência Didática, associada às metodologias EsM, IpC e Sala de Aula Invertida, os alunos obtiveram asserções de conhecimento levando em conta: os seus conhecimentos prévios, os organizadores prévios, a diferenciação progressiva, a reconciliação integradora e a consolidação do conhecimento. 


\section{sala \\ de $\oplus$ em \\ aula foco}

REVISTA ELETRÔNICA

Foram propostas atividades colaborativas em torno de situações-problema, mediando a negociação, a captação de significados e a resolução com a participação do estudante.

Para que ocorra um avanço efetivo e consciente do conhecimento da ciência, produzida a partir do século XX, são urgentes que ocorram atualizações dos currículos, reformas pedagógicas nos métodos de ensino e na elaboração e aplicabilidade de Sequências Didáticas.

\section{REFERÊNCIAS}

AUSUBEL, D. P. Aquisição e retenção de conhecimentos: Uma perspectiva cognitiva. Lisboa: Plátano, 2003.

ARAÚJO, I. S.; MAZUR, E. Instrução pelos colegas e ensino sob medida: uma proposta para o engajamento dos alunos no processo de ensino aprendizagem em física. Caderno Brasileiro de Ensino de Física, v. 30, n. 2: p. 362-384, ago. 2013.

BERGMANN, J.; SAMS, A. Sala de aula invertida: uma metodologia ativa de aprendizagem. Tradução ao português de Afonso Celso da Cunha Serra. 1. ed. Rio de Janeiro: LTC, 2016.

FERREIRA, B. C. S. Metodologias ativas no ensino de Física: a utilização da Peer Instruction em aulas experimentais. 2017. 53f. (Trabalho de Conclusão de Curso)- Licenciatura em Física, Universidade Federal do Espírito Santo, Alegre, 2017.

MOREIRA, M. A. Unidades de Ensino Potencialmente Significativas. 2011d. Disponível em: http:// www.if.ufrgs.br/ moreira/UEPSport.pdf. Acesso em: 23 ago.2017.

MÜLLER, M. G., Metodologias interativas na formação de professores de física: um estudo de caso com o Peer Instruction. 2013. 226 f. Dissertação (Mestrado acadêmico em Ensino de Física) Instituto de Física, Universidade Federal do Rio Grande do Sul, Porto Alegre, (2013).

EXPERIMENTOTECA- Experimento: Alterando A Velocidade de uma Reação. Disponível em: http:// experimentoteca.com/biologia/experimento-alterando-velocidade-de-uma-reacao-quimica/. Acesso em 21 de janeiro de 2019.

NOVAK, G. M. et al. Just-in-Time Teaching: blending active learning whit web technology. [S.I.] 1999. Upper Saddle River, NJ: Prentice Hall, p. 188.

PHET Interactive Simulations. Disponível em: https://phet.colorado.edu/pt_BR/ acesso em 21/03/2019. 